\title{
Trends of homicidal deaths in central Bangkok, Thailand: a 5-year retrospective study
}

\author{
Vorada Sakulsaengprapha ${ }^{1}$, Vichan Peonim ${ }^{2}$ and Wisarn Worasuwannarak ${ }^{2^{*}}$ (D)
}

\begin{abstract}
Background: The aim of this study was to analyze the trends related to homicide victims in central Bangkok, Thailand. These trends were analyzed in terms of general figures and demographics, as well as case-specific details such as time, day, month, weapon, cause of death, location of injury and toxicology. Data was collected using autopsy archives from 2009 to 2013 and specific details were recorded and analyzed statistically.

Results: Major trends identified included generally decreasing rates of homicide, larger proportions of male victims, higher rates of homicide during the hotter months of the summer, and the most common weapon being firearms and sharp force. Also consistent with global trends is a majority of victims being unmarried. Unique to the Thai population, due to social and legal factors, included the frequency of firearm and sharp force injuries, as well as methamphetamine being the most common psychoactive substance found in victim toxicology. Furthermore, many unique points, such as the correlation between the cause of death and the type of force, were made.

Conclusions: Several characteristics of homicide that are similar to global trends have been found in this study. However, some trends were found differed from other countries included the anthropometric data, the types of forces and its relationship to location, as well as which psychoactive substances were detected.
\end{abstract}

Keywords: Forensic pathology, Homicide trend, Homicide crime dynamics, Homicide victimology, Autopsy findings, Homicide toxicology

\section{Background}

A homicide is defined as the "killing of one human being by another" (Merriam-Webster 2016). According to the United Nations Office on Drugs and Crime (UNODC), intentional homicide was the cause of death in almost half a million people globally in 2012 (United Nations Office on Drugs and Crime 2014). This equates to a homicide rate of 6.2 per 100,000 people. There are disparities between different regions around the world within these trends in homicide figures and rates. According to the UNODC 2014 Homicide Statistics, Thailand's intentional homicide rate amounted to 5.0 per 100,000 population, with Bangkok having rates as high as 4.4 per 100,000 in 2006. Overall, Asia's intentional homicide rates are much lower than other

\footnotetext{
*Correspondence: wisarn.wor@mahidol.ac.th

${ }^{2}$ Department of Pathology, Faculty of Medicine Ramathibodi Hospital,

Mahidol University, 270 Rama VI Road, Ratchathewi, Bangkok 10400, Thailand Full list of author information is available at the end of the article
}

regions such as Central and South America. However, Thailand's rate is considerably higher than in some other Southeast Asian countries, such as Timor-Leste and Singapore, whose rates are 3.6 and 0.2 respectively (United Nations Office on Drugs and Crime 2014).

Current data may be limited in that it does not include characteristics and the mechanism of homicide, as well as profiling of the victims and the crime itself. Such fatal violence not only triggers fear among communities, but also victimizes many individuals, including the family of the victim. Having as much data as possible on the homicides occurring in Bangkok, or in any city, can prove to be a valuable tool for raising awareness about the statistics of homicides in the community. Furthermore, making information about such crimes available can serve as a prevention and reduction tool so that individuals in the community can take certain measures to reduce risk factors associated with homicidal crimes. Such 
data can also serve as a catalyst for policy change in areas such as gun control or substance abuse.

As such, there is great interest in the general trends and figures in homicide rates, including time (which includes year, month, day, and period of the day), region, and mechanism. Additionally, victims were profiled according to sex, age, occupation, marital status, birthplace, build, height, weight, and body-mass index (Kumar et al. 2005; Mohanty et al. 2005; Ambade et al. 2007; Cocks and Saayman 2013). It is our hope that this data will provide useful forensic insight into homicide characteristics in Bangkok, Thailand's capital city. These findings will also help shape an understanding of other Asian regions, specifically Southeast Asia, where most countries are developing countries and still have problems with violence. Findings will also help inform how a country's features and idiosyncrasies (socioeconomic, cultural, legal, etc.) may affect its homicide characteristics. An understanding of these relations would then help inform policy effectiveness and how best to reduce crime globally.

\section{Methods}

Homicide case data was collected from autopsy archive in Ramathibodi Hospital, which covers seven districts of Bangkok-Phayathai, Rajathevi, Huaykwang, Dindaeng, Dusit, Bangsue, and Pomprabsatrupai-all located in the center of Bangkok city, included 641,240 from total 5,686,252 individuals in 2013 (Bangkok Metropolitan Administration 2013).

\section{Inclusion criteria}

Screening for homicide cases was done from the total 3430 unnatural deaths (including homicides, suicides, accidents, and all unexplained deaths) that were investigated at the hospital between 2009 and 2013. All homicidal case data from the hospital forensic department's autopsy archives were included to this study.

\section{Exclusion criteria}

The reported cases relating to the 2010 political riots in Bangkok were excluded from this study as they were classified as mass casualties and occur only every few decades. However, there is a report about the characteristics of that event elsewhere (Peonim et al. 2016). Furthermore, homicide cases classified as extra-judicial killings were excluded from analysis. These cases were considered anomalies to the general population analysis of homicides and had the potential of skewing the trends and data obtained.

\section{Data collection}

Reports for homicide cases were subsequently analyzed for information regarding sex, age, victim profile (occupation, marital status, birthplace, build, height and weight), and crime profile (mechanism of injury, time of death, day of week, month, year and toxicology), which may have been recorded from the victim's identification card, death certificate, police report, or the autopsy report itself. Where possible, other relevant information was noted as well.

The data was recorded on a form created to compile each victim's autopsy profile. Subsequently, data was analyzed for statistical figures when applicable. This information was then compared to any available literature.

\section{Results}

\section{Victimology}

On average, homicide cases comprised approximately $3.47 \%$ of the total number of cases recorded. There was a general decrease in the amount of homicide cases with respect to the total number of cases each year. We further analyzed the data with respect to other demographical features including sex and age, as well as occupation, marital status, and birthplace. The vast majority of victims were male (male:female ratio $=5.6: 1$ ), ranging between $70 \%$ and $95 \%$ each year (Table 1).

Analysis of cases shows the average homicide victim age to be 33.4 years old (Fig. 1), with the female average age being slightly higher than the male (37.9 and 32.6 respectively) but not statistically significant $(p=0.134)$. Female age distribution is more evenly distributed. The range of ages spanned 64 years, with the youngest being a 3-year-old male infant and the oldest being a 67 year old female.

Additionally, the majority of the victims (53.8\%) were general employees and were in a nonmarried marital status with a large majority (71.4\%) within this group being identified as single (Fig. 2).

A majority of the victims were registered to be from Central Thailand (57.1\%) with a substantial proportion being from Northeastern Thailand (26.1\%) and smaller amounts from other parts of Thailand. The West and North of Thailand were the least common victim birthplaces. Additionally, there were a few victims who were registered as foreigners, these included Burmese (2.5\%) and Cambodian (1.7\%) citizens. Birthplace was unknown for a small proportion of the victims (Fig. 3).

Table 1 Summary of numbers of cases

\begin{tabular}{lllll}
\hline Year & Total cases & Homicide cases (males) & $\%$ Male & $\%$ Homicide cases \\
\hline 2009 & 704 & $28(24)$ & $85.7 \%$ & $3.98 \%$ \\
2010 & 817 & $30(26)$ & $86.7 \%$ & $3.67 \%$ \\
2011 & 624 & $22(21)$ & $95.5 \%$ & $3.53 \%$ \\
2012 & 656 & $22(18)$ & $81.8 \%$ & $3.35 \%$ \\
2013 & 629 & $17(12)$ & $70.6 \%$ & $2.70 \%$ \\
Total & 3430 & $119(101)$ & $84.9 \%$ & $3.47 \%$ \\
\hline
\end{tabular}




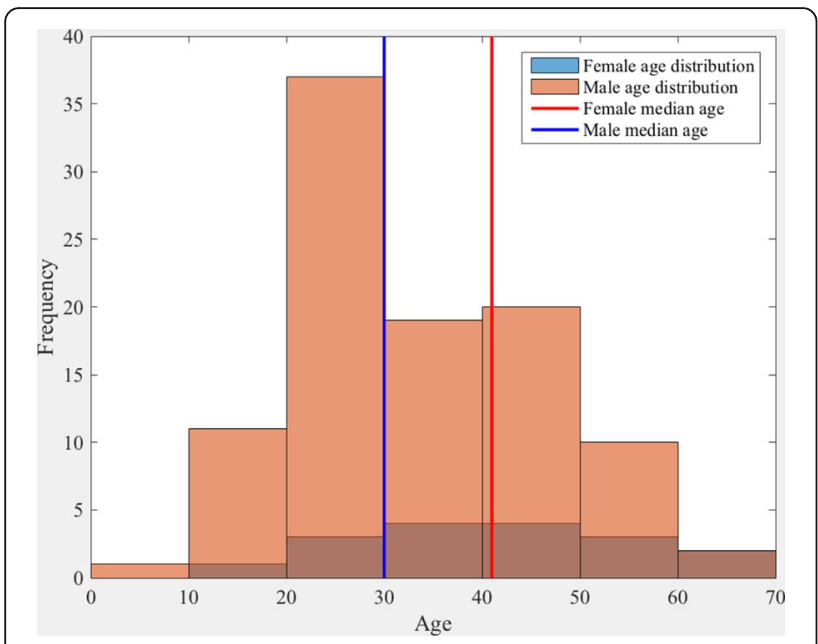

Fig. 1 Distribution of age of victims by sex

Anthropometric characteristics of the victims who were analyzed included height, weight, body mass index (BMI), and build. The average female height was 154.6 $( \pm 5.8) \mathrm{cm}$ with an average weight of $51.5( \pm 13.1) \mathrm{kg}$, and an average BMI of $21.7( \pm 6.1)$. The average male height was $167.7( \pm 9.4) \mathrm{cm}$ with an average weight of $63.8( \pm 13.8) \mathrm{kg}$, and an average BMI of $22.6( \pm 4.3)$. The majority of victims were within the healthy BMI (57.1\%) range, with some in the underweight class $(18.5 \%)$ and overweight class (18.5\%), followed by the more extreme class of obese $(5.9 \%)$. The victims were mostly asthenic in build, as judged by the naked eye (Fig. 4).

\section{Crime dynamics}

There is a general alternating trend in homicide numbers, with maximums during April and October, and the minimum during February. The March to May period, which is summer in Thailand, has the largest amount of homicide deaths, as well as the late rainy season (Table 2).
The days with the greatest frequencies were Sundays (20.2\%) followed by Wednesday and Thursday (17.6\%). Date intervals as well as time of death were subsequently analyzed. Notable is a relatively large drop in the number of homicides during the last third of the month (21st to 31st; 20.2\%), while the numbers seem similar in the first two thirds of the month, with the middle third of the months having slightly greater numbers (Fig. 5).

The greatest amount of homicides occurred during 00.00-05.59 h (33.6\%), and the least occurred during $12.00-17.59 \mathrm{~h}(16.8 \%)$. There was a relatively steady decrease in the amount of cases from 00.00 until $17.59 \mathrm{~h}$, with an increase in the amount for the 18.00-23.59 $\mathrm{h}$ period. It is important as well to note that the time of death and time of incident may not be the same for all cases, depending on the manner of homicide, weapon lethality, etc. (Fig. 6).

Summarized in Fig. 7 are details related to the type of force used regarding the victims' sex. Gunshot wounds and sharp forces were the leading types of force used, followed by blunt force injury. A few cases of manual/ ligature strangulation were observed. With the limited number of cases among female victims, the most common type of force used was firearms followed by sharp force. There were equal numbers of blunt force and manual/ligature strangulation victims. For male victims, the trend is different, with firearms and sharp force having the same leading frequency, followed by blunt force. Only one male victim was found dead by manual/ligature strangulation.

The locations of cause of death in the homicide cases were shown in Table 3. Head and chest trauma were the leading causes, followed by abdomen and neck trauma. No case was found of death by injury to extremities in this study. It further shows that the leading types of force used were gunshots and sharp force, with the exception of blunt force in head traumas.

The death by head trauma was found correlated with blunt force injury with statistical significant $(p<0.001$,

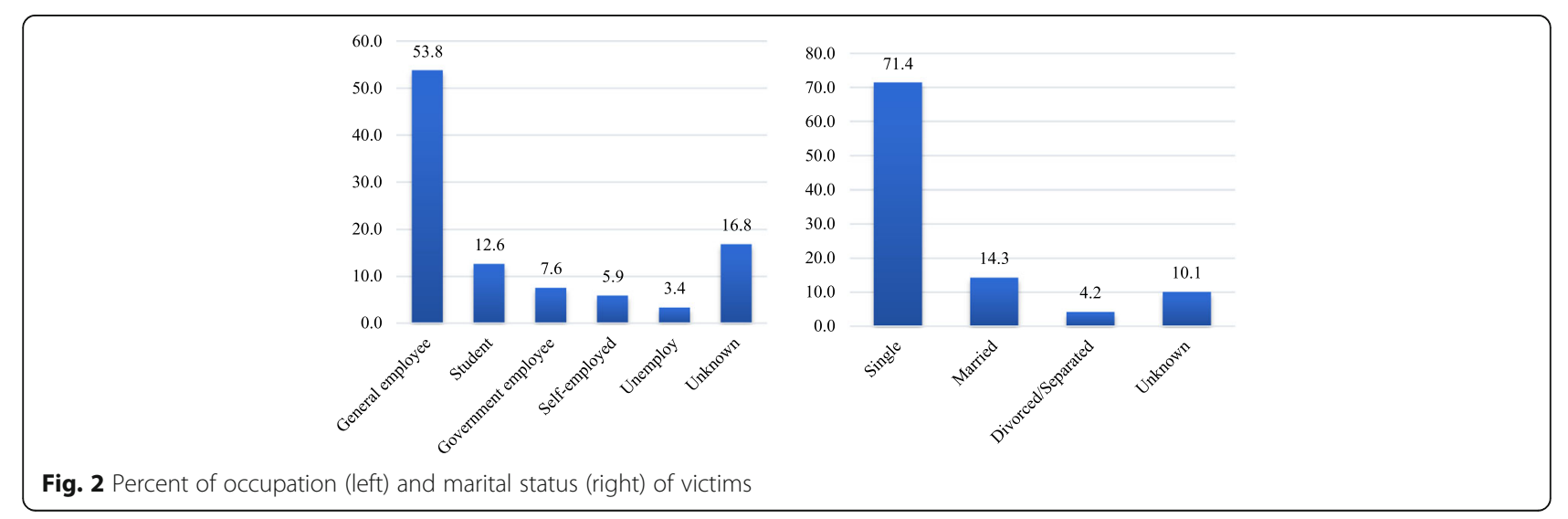




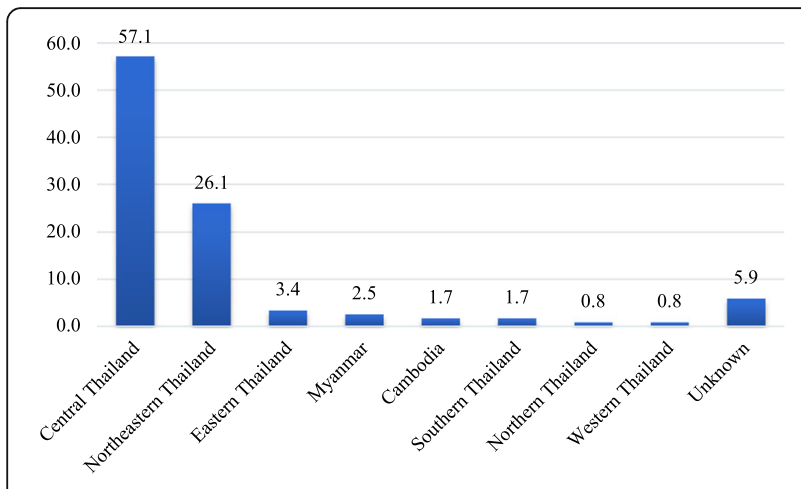

Fig. 3 Percent of birth place of victims

Pearson Chi-Square test). The death by chest trauma and abdominal trauma were also statistical significantly correlated with sharp force injury $(p=0.008$ and $p=$ 0.026 , respectively). In addition, the death by neck injury was correlated with strangulation $(\mathrm{p}<0.001)$ as the neck was involved in all cases that were dead by strangulation.

There were correlations between anthropometric data of the deceased and the cause of death (Table 4). The average weight of the deceased who was dead from chest injury $(65.7 \mathrm{~kg})$ was higher than dead from other location (head, neck and abdomen trauma, average $60.0 \mathrm{~kg}$ ) with statistical significant ( $p=0.041$, Student t-test). In contrast, the average weight of the deceased who was dead from blunt force trauma $(57.3 \mathrm{~kg})$ was lower than the dead from other types of force (gunshot wound, sharp force and strangulation, average $63.4 \mathrm{~kg}$ ) with statistical significant $(p=0.045)$. The height and BMI were not significantly associated with any cause of death and type of force.

\section{Toxicology}

Lastly, blood alcohol content was recorded and summarized (Table 5). Forty-five of the 120 cases did not have their blood alcohol content records available, as intoxication was not suspected at the time of the autopsy. In thirty-two cases (26.89\%), blood alcohol content was found. The majority of cases (with their toxicology reports available) indicated intoxication under the legal definition (> $50 \mathrm{mg} \%$ ). However, the medical definition (>150 $\mathrm{mg} \%$ ), which has a more stringent range, was met with less frequency.

Methamphetamine was the most commonly found drug, with a relatively high rate (6.72\%). Other drugs that were found in victims included Benzodiazepines (Midazolam, Diazepam and Alprazolam), Ephedrine/ Pseudoephedrine, Ketamine and Mitragynine. Morphine and Methadone were not commonly found in the homicidal victims (Table 6). Multiple drug abuse was found in 2 cases, with Midazolam and Alprazolam found in one case, and Diazepam and Alprazolam found in another case.

\section{Discussion}

Having and understanding homicide trends can be helpful in curbing preventable violent crime in a city, which was the intent behind this study. The results of this retrospective study provide unique comprehensive details, not only with regard to demographics, but also concerning victim profiles and their respective homicide profiles. The data and analysis are detailed enough to provide depth, but also are broad enough to create a general overview, which may inspire further study into certain aspects of homicides in Bangkok and cities with similar demographics.

\section{Victimology}

The male-to-female ratio in our study was 5.6:1, slightly lower than findings at the same hospital earlier, from 2003 to 2007, which found a male-to-female ratio of approximately 8.1:1(Pattarapanitchai et al. 2010). The high male-to-female ratio is consistent data presented in the Global Study on Homicide(United Nations Office on Drugs and Crime 2014) as well as with studies in other international cities, including Kuala Lumpur (Kumar et al. 2005), a somewhat comparable city, as it is a major

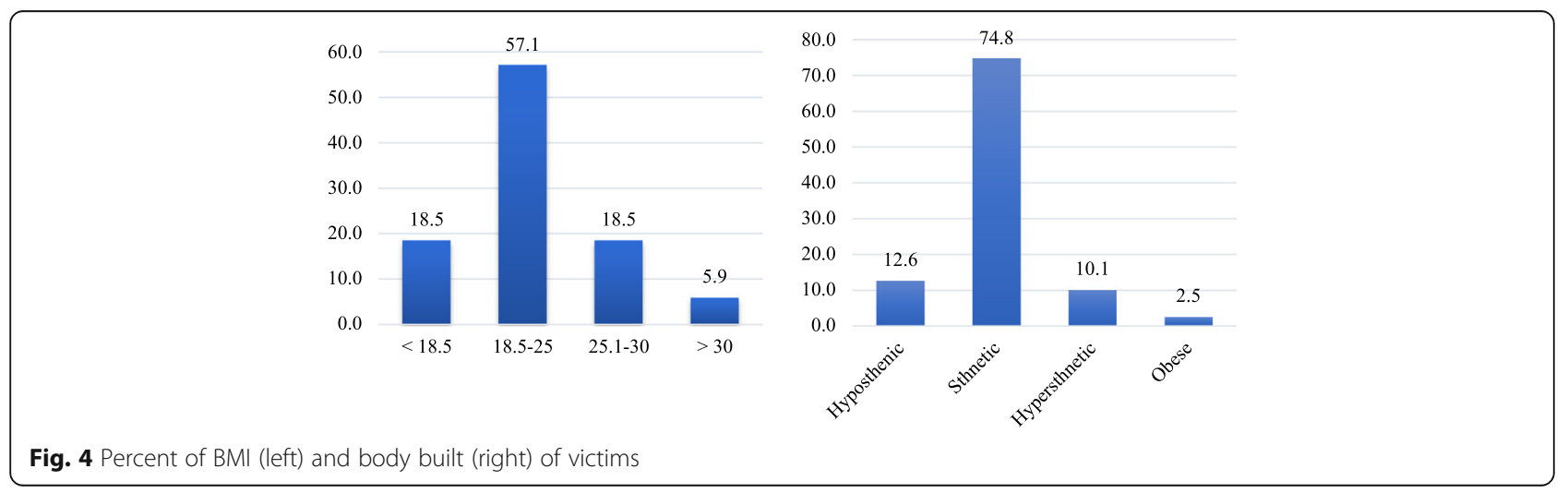


Table 2 Amount of homicides by month and season

\begin{tabular}{|c|c|c|}
\hline Month & $\begin{array}{l}\text { Amount of homicides by } \\
\text { month (\%) }\end{array}$ & $\begin{array}{l}\text { Amount of homicides by } \\
\text { season (\%) }\end{array}$ \\
\hline December & $8(6.7 \%)$ & \multirow{3}{*}{$\begin{array}{l}\text { Winter } \\
24(20.2 \%)\end{array}$} \\
\hline January & 11 (9.2\%) & \\
\hline February & $5(4.2 \%)$ & \\
\hline March & 11 (9.2\%) & \multirow{3}{*}{$\begin{array}{l}\text { Summer } \\
35(29.4 \%)\end{array}$} \\
\hline April & 14 (11.8\%) & \\
\hline May & 10 (8.4\%) & \\
\hline June & $6(5.0 \%)$ & \multirow{3}{*}{$\begin{array}{l}\text { Early rainy } \\
25(21.1 \%)\end{array}$} \\
\hline July & $6(5.0 \%)$ & \\
\hline August & 13 (10.9\%) & \\
\hline September & 12 (10.1\%) & \multirow{3}{*}{$\begin{array}{l}\text { Late rainy } \\
35(29.4 \%)\end{array}$} \\
\hline October & $14(11.8 \%)$ & \\
\hline November & 9 (7.6\%) & \\
\hline
\end{tabular}

city located in the same region of Southeast Asia, as well as Pretoria (South Africa) and several cities in India (Mohanty et al. 2005; Ambade et al. 2007; Cocks and Saayman 2013).

Findings by Roth (2012) showed that the percent of male homicide victims exceeded that of women consistently around the world, with larger differences between males and females in low and middle-income countries(Roth 2012). Our findings of a steep male-female ratio of homicide victims in Thailand, an upper middle-income country since 2011 according to the World Bank (The World Bank 2016), support this. Earlier findings of a slightly steeper homicide sex ratio, closely following the country's economic growth and this victim sex ratio which could further affirm or dispel Roth's findings, may prove to be an impactful sociological phenomenon to study.

According to the U.S. Department of Justice, vulnerability to violent crime victimization generally decreases with age after a peak in the teenage years (Perkins 1997), which may partly explain the slightly right-skewed age distribution as seen in Fig. 1. Again, this trend may be a result of lifestyle factors such as socialization patterns, drug/alcohol use, impulsivity, etc., even though the differences between the general population and homicide victim ages are most likely not drastic enough to be a critical aspect of victim vulnerability. Compared to data reported by Eisner (2003), the average victim age in the United States was 32.3 years and 34 years in Stockholm, similar to our findings (33.4 years)(Eisner 2003). Eisner reports that this number has generally not changed since the sixteenth century. Therefore, it is clear that our data is consistent with not only Thai demographics but also the profile of typical homicide victims as reported by several years of data collection.

Our findings are consistent with the popular assumption that people who are in non-married marital statuses (single or divorced/separated) are at greater risk of homicides. According to a study of male homicide victims in the United States, non-married individuals have a higher relative risk, once fitted to the Cox proportional hazards model, along with other covariates like social isolation, education, and employment status(Kposowa et al. 1994). Because this phenomenon is consistent globally, there is reason to believe that the social mechanism underlying the trend is the same throughout. The authors of the study have speculated that this trend can be explained by Durkheim's theory relating attachment to crime, although there is not much evidence to support this. It is also unclear if the high incidence of homicide among single men is due to their marital status or because they were young (Froeling 2007).

Trends pertaining to the victims' place of birth are also consistent with the movement of Thai people, notably the urban agglomeration of Bangkok by people from the Northeast. The greatest proportion of victims in this study being from central and northeastern Thailand is consistent with population data, in that the largest segments of the population of people living in Bangkok are those from the central and northeastern

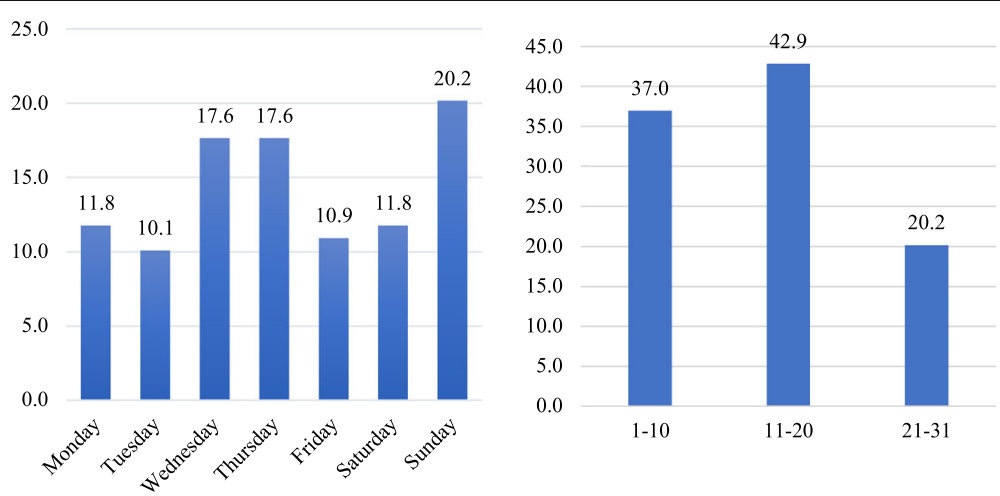

Fig. 5 Percent of days (left) and date interval (right) of death of victims 


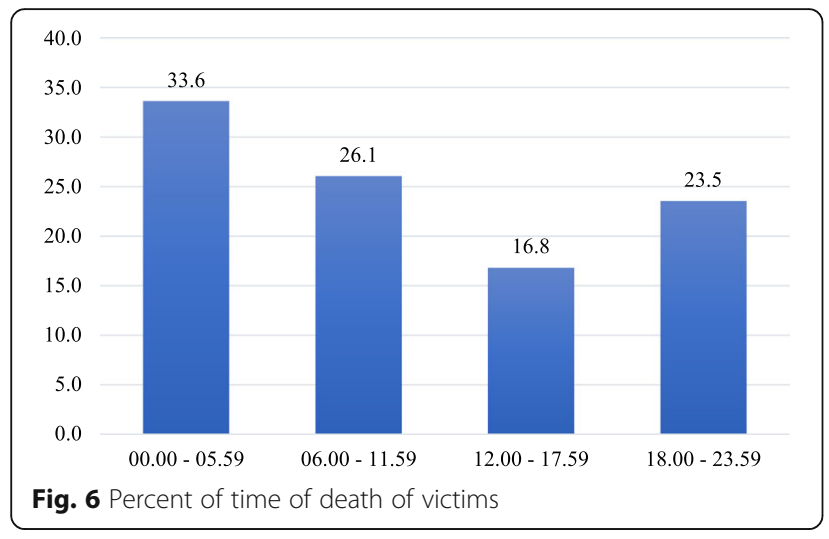

areas of the country(Tangcholthip 2006). These trends suggest that there is no apparent demographic targeting of homicide victims, but rather that homicide victims are targeted either randomly or for other reasons not related to place of birth. Burmese and Cambodian victims found in this study may be explained by their migration to Thailand seeking employment, mostly as general employees.

The homicide victims' average BMI fell within the WHO's normal Asian BMI range of 18.5-25(Barba et al. 2004). However, there was a significantly larger proportion of both male $(15.8 \%)$ and female $(33.3 \%)$ victims with a BMI less than 18.5 compared to their respective national averages $(9.4 \%$ and $7.6 \%$, respectively) Aekplakorn 2010. This difference was much more pronounced for female victims. Previous research on American women has shown a positive correlation between BMI and crime victimization and having encountered homicide attempts(Brewerton et al. 2015), contrary to our victim BMI distribution. Because the number of female victims is relatively low compared to male victims, such correlation with crime victimization may not be very strong. However, given the existing trends and large discrepancy between underweight victims compared to the national average, there may be a systematic explanation,

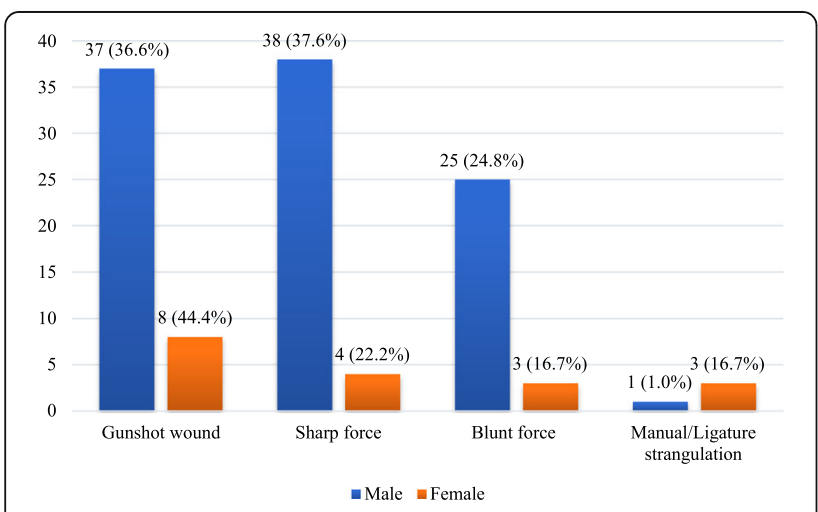

Fig. 7 Percent of homicides by sex and type of force
Table 3 Cause of death categorized by type of force and location

\begin{tabular}{|c|c|c|c|c|c|c|}
\hline \multirow{2}{*}{$\begin{array}{l}\text { Cause of } \\
\text { death }\end{array}$} & & \multicolumn{4}{|c|}{ Type of force } & \multirow[t]{2}{*}{ Total } \\
\hline & & $\begin{array}{l}\text { Gunshot } \\
\text { wound }\end{array}$ & $\begin{array}{l}\text { Sharp } \\
\text { force }\end{array}$ & $\begin{array}{l}\text { Blunt } \\
\text { force }\end{array}$ & $\begin{array}{l}\text { Manual/ Ligature } \\
\text { Strangulation }\end{array}$ & \\
\hline \multirow[t]{2}{*}{ Head } & $\mathrm{N}$ & 14 & 5 & $27^{*}$ & 0 & 46 \\
\hline & $\%$ & $31.1 \%$ & $11.9 \%$ & $96.4 \%$ & $0.0 \%$ & $38.7 \%$ \\
\hline \multirow[t]{2}{*}{ Chest } & $\mathrm{N}$ & 19 & $21^{*}$ & 1 & 0 & 41 \\
\hline & $\%$ & $42.2 \%$ & $50.0 \%$ & $3.6 \%$ & $0.0 \%$ & $34.5 \%$ \\
\hline \multirow[t]{2}{*}{ Abdomen } & $\mathrm{N}$ & 8 & $10^{*}$ & 0 & 0 & 18 \\
\hline & $\%$ & $17.8 \%$ & $23.8 \%$ & $0.0 \%$ & $0.0 \%$ & $15.1 \%$ \\
\hline \multirow[t]{2}{*}{ Neck } & $\mathrm{N}$ & 4 & 6 & 0 & $4^{*}$ & 14 \\
\hline & $\%$ & $8.9 \%$ & $14.3 \%$ & $0.0 \%$ & $100.0 \%$ & $11.8 \%$ \\
\hline \multirow[t]{2}{*}{ Total } & $\mathrm{N}$ & 45 & 42 & 28 & 4 & 119 \\
\hline & $\%$ & $37.8 \%$ & $35.3 \%$ & $23.5 \%$ & $3.4 \%$ & $100.0 \%$ \\
\hline
\end{tabular}

*statistical significant correlation $(p<0.05)$

whether sociological, psychological, or biological, for this phenomenon.

Most publications on homicide victimology have not focused on the demographics or anthropomorphological characteristics of the victims, therefore making it difficult to establish or confirm any trends. However, such characteristics reveal that some of the statistics of homicide victims deviate from the general population.

\section{Crime dynamics}

Our findings are consistent with other studies about increases in violent crimes during the summer/hotter months(Anderson 2001) (April, the hottest month in Thailand, had the largest number of homicides). However, it can be seen that the gaps between the different seasons of the year are not significantly large, with the late rainy season of September to November having almost as many cases. It has been found that, statistically, warmer cities do not experience as much change in terms of the number of crimes(Ranson 2014), which may explain the generally even monthly distribution of homicides.

Furthermore, there are several interesting aspects included in our study which are rarely studied extensively. For example, the date interval in which the homicide cases occurred presents an interesting issue. There may possibly be a socioeconomic explanation behind why the last third of the month had the lowest homicide frequency, but further studies with larger sample sizes, as well as a more detailed exploration of the issue, may be needed to present a conclusive answer. With this, it may also be important to further note any special holidays, to observe whether or not a correlation between the occasion and the homicide numbers exists. Additionally, our findings of more homicides during the night time are 
Table 4 The anthropometric data categorized by location and type of force

\begin{tabular}{|c|c|c|c|c|c|c|c|c|}
\hline \multirow[t]{2}{*}{ Anthropometric } & \multicolumn{4}{|c|}{ Location } & \multicolumn{4}{|c|}{ Type of force } \\
\hline & Head & Neck & Chest & Abdomen & GSW & Blunt & Sharp & Strangulation \\
\hline Height & 165.2 & 159.7 & 167.2 & 168.6 & 166.6 & 164.6 & 166.5 & 156.3 \\
\hline Weight & 59.3 & 52.9 & $65.7^{*}$ & 67.5 & 64.0 & $57.3^{*}$ & 63.9 & 51.8 \\
\hline BMI & 21.5 & 20.8 & 23.6 & 23.7 & 23.1 & 20.9 & 23.0 & 21.4 \\
\hline
\end{tabular}

*statistical significant correlation $(p<0.05)$

confirmed by numerous statistics of time correlation regarding violent crime in adult offenders (Office of Juvenile Justice and Delinquency Prevention 2014). The peak time in homicides occurring at night in our study may possibly be explained by alcohol consumption leading to aggression, or by greater convenience for escape of criminals. Both hypotheses are currently understudied, and thus if extensively studied, may yield beneficial information to help mitigate issues of violent crime.

Analysis of the weapon used in each case has also demonstrated results consistent with previous studie$\mathrm{s}$ (Kristoffersen et al. 2014). The finding that gunshot wounds are the most common type of force is consistent with the research showing firearms as the most commonly used weapons to kill victims in many countries, including the United States (Pettler 2015) and Italy (Verzeletti et al. 2014). Compared to the United States, we see that the murder weapons used in our cases seem to be more evenly spread, whereas in the United States, in 2014, firearms were responsible for approximately $67.9 \%$ of homicide cases reported,

Table 5 Alcohol content in victims

\begin{tabular}{|c|c|c|c|c|}
\hline Year & $\begin{array}{l}\text { Blood } \\
\text { alcohol } \\
\text { content } \\
\text { positive } \\
(\%)\end{array}$ & $\begin{array}{l}\text { Intoxicated } \\
\text { (> } 50 \text { mg\%) } \\
\text { (\% of positive } \\
\text { cases) }\end{array}$ & $\begin{array}{l}\text { Intoxicated } \\
\text { (>150 mg\%) } \\
\text { (\% of positive } \\
\text { cases) }\end{array}$ & $\begin{array}{l}\text { Average blood } \\
\text { alcohol content of } \\
\text { those with alcohol } \\
\text { content (SD) (mg\%) }\end{array}$ \\
\hline $\begin{array}{l}2009 \\
(n= \\
28)\end{array}$ & 11 (39.3\%) & $9(81.8 \%)$ & $2(18.2 \%)$ & $108.77(85.4)$ \\
\hline $\begin{array}{l}2010 \\
(n= \\
30)\end{array}$ & 7 (23.3\%) & $6(85.7 \%)$ & $2(28.6 \%)$ & $128.96(86.7)$ \\
\hline $\begin{array}{l}2011 \\
(n= \\
22)\end{array}$ & $4(18.2 \%)$ & $3(75.0 \%)$ & $2(50.0 \%)$ & 167.06 (101.5) \\
\hline $\begin{array}{l}2012 \\
(n= \\
22)\end{array}$ & $8(36.4 \%)$ & $4(75.0 \%)$ & $4(50.0 \%)$ & $181.91(154.3)$ \\
\hline $\begin{array}{l}2013 \\
(n= \\
17)\end{array}$ & $2(11.8 \%)$ & $2(100.0 \%)$ & $0(0.0 \%)$ & 82.86 (23.6) \\
\hline $\begin{array}{l}\text { Total } \\
(n= \\
119)\end{array}$ & $32(26.9 \%)$ & $24(75.0 \%)$ & 10 (31.3\%) & $137.14(106.4)$ \\
\hline
\end{tabular}

Note: As defined in Thailand the range legally defined for intoxication is > $50 \mathrm{mg} \%$, and the range medically defined is $>150 \mathrm{mg} \%$ followed by the use of knives or cutting instruments, blunt objects, and personal weapons (Federal Bureau of Investigation 2014). Findings of minority groups, such as indigenous South Australians, suggest that gunshot deaths there were different, where firearm deaths were slightly less common than blunt and sharp force trauma (Temlett and Byard 2012). From these differences, it is evident that injury mechanism distributions depend on pragmatic factors, such as what resources are available in each culture.

Interestingly, although gunshot wounds and sharp force were the most common types of force used, this was not the case for head trauma. Even though head gunshot wounds have very high mortality rates (Spitz and Spitz 2006), the chest was more commonly affected by gunshot wounds in this study. Blunt force injury to the head was significantly more common in our study, which is consistent with previous findings that the head is the most common site of fatal blunt force injuries(Ambade and Godbole 2006). However, contributing factors may include the difficulty of using sharp objects to penetrate the skull, the availability of multiple objects, and the ability to use bare hands to cause fatal injuries to the head.

Similar to firearm trends in other countries mentioned(Myint et al. 2014), it is evident that firearms contribute significantly to homicide rates in Bangkok. It has been recently reported that Bangkok has a high per capita gun-murder rate when compared with other Asian countries like Brunei, Singapore, India, and

Table 6 List of substances found in toxicology reports

\begin{tabular}{lll}
\hline Substance & Total & \% of total $(n=119)$ \\
\hline Methamphetamine & 8 & $6.72 \%$ \\
Midazolam & 5 & $4.20 \%$ \\
Diazepam & 4 & $3.36 \%$ \\
Ephedrine/pseudoephedrine & 4 & $3.36 \%$ \\
Alprazolam & 3 & $2.52 \%$ \\
Amphetamine & 2 & $1.68 \%$ \\
Ketamine & 2 & $1.68 \%$ \\
Mitragynine & 2 & $1.68 \%$ \\
Morphine & 1 & $0.84 \%$ \\
Methadone & 1 & $0.84 \%$ \\
\hline
\end{tabular}


China(United Nations Office on Drugs and Crime 2014). Studies have found a correlation between gun availability and homicide rates, notably in countries such as the United States where such weapons are available for purchase by the general population. Although much less than the United States, Thailand's private gun ownership (both licit and illicit) is $15.6 \%$, putting it at 11th globally in terms of the number of privately owned guns, and 39th globally in terms of rate of private gun ownership, as of 2007 (Alpers and Wilson 2016).

Additionally, it has been found that income inequality and social capital, when other factors like poverty and firearm availability are controlled for, is related to firearm violent crime (Kennedy et al. 1998). Given that income inequality in Thailand is growing and is among the highest in Southeast Asia (Bird et al. 2011), the high firearm homicide proportion may not be entirely surprising. However, it is also very likely that because Bangkok's poverty is much lower compared to other regions of Thailand, and due to its homogeneous characteristics, this relationship with income inequality is moderated, precluding firearm deaths from being much greater than deaths due to other mechanisms, like sharp force. Nevertheless, these findings are alarming, and it may be useful to further study whether policy changes regarding gun ownership and use should be made. Additionally, policies that address broader issues like income inequality may also prove to be beneficial and of interest to the government.

Our study found that the death from head trauma was statistical significantly correlated with blunt force injury while the death from chest trauma and abdominal trauma were statistical significantly correlated with sharp force injury. These findings confirmed the previous study (Ambade and Godbole 2006) that the head is an important target of attack with the fists or weapons without sharp edge while the chest and abdomen were most targeted by sharp or piecing weapons.

For the anthropometric data and the cause of death, it was surprising that persons who died from chest trauma had higher average weight than other traumas statistical significantly. It was possible that the chest is a prominent and wide target area in the man with large body. On the other hand, it was not surprising that the deceased who was dead from blunt force injury had lower weight than the other types of force statistical significantly. This could be because the smaller persons have a tendency to be assaulted or bullied by others (White and Mason 2012).

\section{Toxicology}

In cases where toxicology was analyzed, a large proportion was deemed alcoholic intoxication. This may implicate alcohol use as a correlate of aggressive behavior, as previous studies have found, and that alcohol may lead to poor judgment and decision-making(Hedlund et al. 2014) in addition to homicidal activities (Parker and Cartmill 1998). Compared to other substances found, alcohol made up a large majority, which is consistent with past studies(Verzeletti et al. 2014). With a number of victims being deemed intoxicated, anger or poor judgment during a drunken altercation may be possible factors for homicide on the part of both perpetrator and victim.

The presence of drugs in homicide victims such as those found in approximately a quarter of the victims in our study can be indicative of several factors related to homicide. Psychoactive substances are linked to certain distal factors, such as lifestyle and systemic violence, which may increase the risk for violence and homicide. Additionally, there is a strong association between offenders and victims in terms of co-intoxication (Darke 2010). Therefore, toxicology results can provide not only good insight into circumstances around the case, but also serve as markers of violence and the manner of death. Trends in common drugs found in homicide victims have been found to vary across different culture$s$ (Darke et al. 2009). For this study, the most common drug found being methamphetamine is not a surprising result, as it has been shown that $Y a B a$, which is the Thai name referring to methamphetamine tablets, is the most widely consumed illicit drug in Thailand, with consumption on the rise among teenagers (Windle 2015).

Additionally, a link has been drawn previously between drug use and firearm deaths (Darke 2010), which may be explained by distal factors such as a predisposition for violence in drug users, leading to firearm-related violence. Our study found both high amounts of firearm deaths as well as a relatively significant amount of psychoactive drugs present in toxicology reports. Such findings, in addition to Thailand's current fight against both drugs and firearm violence, suggest a need for further study as well as adjustment in policy. Addressing either or both may prove to be beneficial in reducing homicide rates, as well as crime in general.

However, it is also important to note that multiple cases did not have toxicological (and alcohol content) data, as the attending pathologist did not suspect alcohol content or psychoactive substances to be of concern. Evidently, the data available for analysis was not extensive, and therefore a more detailed analysis with a larger sample size would be required to confirm the relationship between alcohol and drugs in the victims, and the circumstances surrounding their homicide.

\section{General discussion}

As seen, many perspectives are provided related to homicides and their circumstances. Several known trends, like cause of death pertaining to specific organ locations, where head injuries are the most common cause, are 
also consistent with other studies (Vij et al. 2010; Kristoffersen et al. 2014). Other trends that show cultural variation, such as psychoactive substances as well as those that have not been extensively studied in the past were also studied here. Many of these trends are significant and may have larger implications on public policy as well as law enforcement tactics.

However, due to the limited number of cases available, as well as limited or inconsistently available data on crime elements such as location of death, the ability to definitively conclude correlation or causation is reduced. Additionally, due to limitations of case data, especially court verdicts and final investigative conclusions, we are unable to produce the whole picture for characterizing homicides in Bangkok. However, it should also be noted that the jurisdictional area in this study, representing 7 of the 50 districts in Bangkok, are centrally located with a dense population, ensuring the generalizability of the trends we have presented.

\section{Conclusions}

Through our retrospective analysis of homicide cases from 2009 to 2013, we were able to confirm several trends, including demographic trends and seasonal patterns, as well as identifying interesting deviations from such trends.

Several characteristics of homicide that are similar to global trends have been found in this study, including occurrence in the summer, and alcohol and drug use. Other risk factors consistent with global trends that were found include being male and unmarried. Other trends which were explored that differ from other countries included the types of forces (mostly gunshot and sharp force injuries) and its relationship to location (notably blunt force injury at the head trauma and sharp force injury and the chest and abdomen trauma), as well as the anthropometric data and the correlation to the cause of death (notably heavy weight associated with chest trauma and light weight associated with blunt force injury). The psychoactive substances were also detected in the victims, especially methamphetamine. However, these differences may be linked to local characteristics such as laws and pragmatic factors like weapon or drug availability. We hope that our findings serve to not only inform people of existing trends relating to homicides in Bangkok, but also as a source of discussion for the public to generate positive change in our country.

\section{Acknowledgements}

The authors would like to thank our colleagues, including Forensic Division staff and officers, for the support they have given us.

\section{Funding}

The authors declared no funding.
Availability of data and materials

Not applicable.

\section{Authors' contributions}

VS is initiating the study, collecting the data, analyzing the data and writing the manuscript. WW is registering to the ethical approval committee, analyzing the data, writing the manuscript and submitting the manuscript. $V P$ is initiating the study and guiding the study design. All authors read and approved the final manuscript.

\section{Authors' information}

Not applicable.

\section{Ethics approval and consent to participate}

The analyses in this report have been approved by the Ethical Clearance Committee on Human Rights Related to Research Involving Human Subjects, Faculty of Medicine, Ramathibodi Hospital, Mahidol University (MURA2016/457 N1).

\section{Consent for publication}

Not applicable.

\section{Competing interests}

The authors declare that they have no competing interests.

\section{Publisher's Note}

Springer Nature remains neutral with regard to jurisdictional claims in published maps and institutional affiliations.

\section{Author details}

'Whiting School of Engineering, Johns Hopkins University, 3400 North Charles Street, Baltimore, MD 21218, USA. ²Department of Pathology, Faculty of Medicine Ramathibodi Hospital, Mahidol University, 270 Rama VI Road, Ratchathewi, Bangkok 10400, Thailand.

Received: 20 October 2017 Accepted: 23 January 2018

Published online: 02 February 2018

\section{References}

Alpers P, Wilson M (2016) Thailand — Gun Facts, Figures and the Law. In: Sydney Sch. Public Heal. Univ. Sydney. http://www.gunpolicy.org/firearms/region/ thailand. Accessed 10 Jan 2017

Ambade VN, Godbole HV (2006) Comparison of wound patterns in homicide by sharp and blunt force. Forensic Sci Int 156:166-170. https://doi.org/10.1016/j. forsciint.2004.12.027

Ambade VN, Godbole HV, Kukde HG (2007) Suicidal and homicidal deaths: a comparative and circumstantial approach. J Forensic Legal Med 14:253-260. https://doi.org/10.1016/j.jcfm.2006.08.001

Anderson CA (2001) Heat and violence. Curr Dir Psychol Sci 10:33-38. https://doi. org/10.1111/1467-8721.00109

Bangkok Metropolitan Administration (2013) Population and house statistics in Bangkok classified by district in December 2013. http://203.155.220.230/ bmainfo/esp/pop/population_Dec56.htm

Barba C, Cavalli-Sforza T, Cutter J et al (2004) Appropriate body-mass index for Asian populations and its implications for policy and intervention strategies. Lancet 363:157-163. https://doi.org/10.1016/S0140-6736(03)15268-3

Bird K, Hattel K, Sasaki E, Attapich L (2011) Poverty, income inequality, and microfinance in Thailand. Asian Development Bank

Brewerton TD, Neil PMO, Dansky BS, Kilpatrick DG (2015) Extreme Obesity and its Associations with Victimization, PTSD, Major Depression and Eating Disorders in a National Sample of Women. J Obes Eat Disord 1:1-9

Cocks J, Saayman G (2013) The incidence, pathology of trauma and victim profiles of homicidal deaths in Pretoria, South Africa (2007-2008). Med Sci Law 53:61-66. https://doi.org/10.1258/msl.2012.012027

Darke S (2010) The toxicology of homicide offenders and victims: a review. Drug Alcohol Rev 29:202-215. https://doi.org/10.1111/j.1465-3362.2009.00099.x

Darke S, Duflou J, Torok M (2009) Drugs and violent death: comparative toxicology of homicide and non-substance toxicity suicide victims. Addiction 104:1000-1005. https://doi.org/10.1111/j.1360-0443.2009.02565.x

Eisner M (2003) Long-term historical trends in violent crime. Crime and Justice 30:83-142. https://doi.org/10.2307/1147697 
Federal Bureau of Investigation (2014) Murder Victims by Weapon, 2010-2014. https://ucr.fbi.gov/crime-in-the-u.s/2014/crime-in-the-u.s.-2014/tables/ expanded-homicide-data/expanded_homicide_data_table_8_murder_ victims by weapon_2010-2014.xls. Accessed 12 Jul 2016

Froeling KT (2007) Criminology research focus. Nova Publishers, New York

Hedlund J, Ahlner J, Kristiansson M, Sturup J (2014) A population-based study on toxicological findings in Swedish homicide victims and offenders from 2007 to 2009. Forensic Sci Int 244:25-29. https://doi.org/10.1016/j.forsciint.2014.07.015

Kennedy BP, Kawachi I, Prothrow-Stith D et al (1998) Social capital, income inequality, and firearm violent crime. Soc Sci Med 47:7-17. https://doi.org/10. 1016/S0277-9536(98)00097-5

Kposowa AJ, Singh GK, Breault KD (1994) The effects of marital status and social isolation on adult male homicides in the United States: evidence from the National Longitudinal Mortality Study. J Quant Criminol 10:277-289. https:// doi.org/10.1007/BF02221213

Kristoffersen S, Lilleng PK, Maehle BO, Morild I (2014) Homicides in western Norway, 1985-2009, time trends, age and gender differences. Forensic Sci Int 238:1-8. https://doi.org/10.1016/j.forsciint.2014.02.013

Kumar V, Li AKM, Zanial AZ et al (2005) A study of homicidal deaths in medicolegal autopsies at UMMC, Kuala Lumpur. J Clin Forensic Med 12:254-257. https://doi.org/10.1016/j.jcfm.2005.02.007

Merriam-Webster (2016) Homicide. http://www.merriam-webster.com/dictionary/ homicide. Accessed 10 Apr 2016

Mohanty MK, Kumar TSM, Mohanram A, Palimar V (2005) Victims of homicidal deaths - an analysis of variables. J Clin Forensic Med 12:302-304. https://doi. org/10.1016/j.jcfm.2005.03.007

Myint S, Rerkamnuaychoke B, Peonim V, et al (2014) Fatal firearm injuries in autopsy cases at central Bangkok, Thailand: A 10-year retrospective study. J Forensic Leg Med. doi: https://doi.org/10.1016/j.jflm.2014.09.002

Aekplakorn W (ed) (2010) Thailand National Health and Examination Survey IV 2008-2009. The Graphico Systems, Nonthaburi

Office of Juvenile Justice and Delinquency Prevention (2014) Comparing offending by adults \& juveniles. OJJDP Stat. Brief. B, In http://www.ojjdp.gov/ ojstatbb/offenders/qa03401.asp?qaDate $=2010$

Parker RN, Cartmill RS (1998) Alcohol and homicide in the United States 19341995-or one reason why U.S. Rates of violence may be going down. J Crim Law Criminol 88:1369-1398

Pattarapanitchai N, Tiensuwan M, Riengrojpitak S (2010) A retrospective study on homicidal autopsy cases at ramathibodi hospital in bangkok Thailand. Chiang Mai J Sci 37:282-292

Peonim V, Srisont S, Udnoon J et al (2016) Entrance and exit wounds of high velocity bullet: an autopsy analysis in the event of dispersing the mass rally in Bangkok Thailand, may 2010. Legal Med 23:10-16. https://doi.org/10.1016/ j.legalmed.2016.08.010

Perkins CA (1997) Age Patterns of Victims of Serious Violent Crime. US Department of Justice, Office of Justice Programs, Bureau of Justice Statistics

Pettler LG (2015) Crime scene staging dynamics in homicide cases. CRC Press, Boca Raton

Ranson M (2014) Crime, weather, and climate change. J Environ Econ Manage 67:274-302. https://doi.org/10.1016/j.jeem.2013.11.008

Roth R (2012) American homicide. Harvard University Press, Cambridge

Spitz WU, Spitz DJ (2006) Spitz and Fisher's medicolegal investigation of death: guidelines for the application of pathology to crime investigation. Charles C Thomas Publisher, Springfield

Tangcholthip K (2006) Who are the people of Bangkok

Temlett J, Byard RW (2012) Homicide among indigenous south Australians: a forty-year study (1969-2008). J Forensic Legal Med 19:445-447. https://doi. org/10.1016/j.flm.2011.12.027

The World Bank (2016) Thailand Overview. http://www.worldbank.org/en/ country/thailand/overview. Accessed 10 Jan 2017

United Nations Office on Drugs and Crime (2014) Global study on homicide 2013. United Nations Publication, Vienna

Verzeletti A, Russo MC, De Ferrari F (2014) Homicide-suicide in Brescia County (northern Italy): a retrospective study from 1987 to 2012. J Forensic Legal Med 25:62-66. https://doi.org/10.1016/j.jflm.2014.04.014

Vij A, Menon A, Menezes RG et al (2010) A retrospective review of homicides in Mangalore, South India. J Forensic Legal Med 17:312-315. https://doi.org/10. 1016/j.jlm.2010.04.012

White R, Mason R (2012) Bullying and gangs. Int J Adolesc Med Health 24:57-62. https://doi.org/10.1515/ijamh.2012.008

Windle J (2015) Drugs and drug policy in Thailand. Foreign Policy at Brookings:1-16

\section{Submit your manuscript to a SpringerOpen ${ }^{\circ}$ journal and benefit from:}

- Convenient online submission

- Rigorous peer review

- Open access: articles freely available online

- High visibility within the field

- Retaining the copyright to your article

Submit your next manuscript at springeropen.com 